\title{
Synthesis and Characterization of Complexes of Remodulated Polyvinyl Alcohol Conjugates
}

\author{
Dr. Gopalkrushna Haribhau Murhekar \\ Organic Synthesis Division, PG Department of chemistry, Government Science College, Gadchiroli \\ (M. S.), India
}

\begin{abstract}
The synthesis and characterization of complexes of remodulated polyvinyl alcohol conjugates was studied by using chemical method. Characterizations of RPVA were carried out by using FTIR, XRD. It showed that, for RPVAs, compatibility between the amorphous components of both homopolymers is possible. Thus, it can be suggested that the crystal forms in PVA do not prevent the compatibility between amorphous regions of the two polymers. Fourier transform infrared FTIR spectra of all polymer conjugates under investigation were recorded between 400 and $4000 \mathrm{~cm}^{-}$.
\end{abstract}

Keywords: Remodulated Polyvinyl Alcohol, FTIR, XRD, RPVA and CRPVA

\section{INTRODUCTION}

Polymer complexes have been given a great deal of attention in recent years [1-3]. Polyvinyl alcohol (ethanol homopolymer) which considered as moderate adhesive is a water - soluble resin. PVA is a polymer with exceptional properties such as water solubility, biodegradability, biocompatibility, nontoxicity and non-carcinogenity that possesses the capability to form hydrogels by chemical or physical methods [4-6]. Its fields of applicability were widely broadened during the later years due to the development of medicine.

Poly (vinyl alcohols), (PVA) are widely used in polymer science fields because the advantages of PVA are water-soluble polymer, biodegradable polymer and low toxic [7-8]. The chemical modification has subsequently applied to improve the properties of macromolecules, leading to many applications of PVA, especially made in polymer hydrogel [9]. Hydrogels are three-dimensional networks of dispersed polymer chains in water that are held together by physical or chemical crosslink. They are generally made from hydrophilic polymers that are subsequently cross linked producing networks characterised by a high degree of swelling without dissolution and it was used in medical applications due to their high water content and hydrophilic nature.

Polymer which is Polyvinyl alcohol or known as PVA is a non-toxic, water soluble, bio compatible and biodegradable synthetic polymer have been widely used in biomedical field. PVA has been better fiber-forming and highly hydrophilic properties and its fibers have been commercialized since the 1950s [10]. Polymers have received much experimental attention, due to their unique properties, such as low density, ability to form intricate shapes, versatile electric properties and low manufacturing cost [11].In the present research work, synthesis and characterizations of remodulated Polyvinyl Alcohol complexes with transition metal ions was carried out and its characterization using FTIR, and XRD was used

\section{Material AND Methods}

All the chemicals used in this work were obtained from Merck. Following advance methods are used for remodulation of PVA

\subsection{Hydroxyethylation of PVA with Chloroethanol}

Chemical Required: Na metal, ethanol, anhydrous DMSO, chloroethanol

\section{Procedure}

In $200 \mathrm{ml}$ ethanol the amount of $10 \mathrm{~g}$ of $\mathrm{Na}$ metal was dissolved. The excess of ethanol was evaporated in vaccum. The remaining sodium ethoxide was solubilized into $200 \mathrm{ml}$ of anhydrous 
DMSO under nitrogen, and $14 \mathrm{~g}$ of PVA was added. The mixture was stirred vigorously to give a gelatinous product. The residual alcohol was removed under vaccum. The resulting sodium polyvinyl alcoholate was dissolved in $200 \mathrm{ml}$ DMSO and $26 \mathrm{ml}$ of freshly distilled chloroethanol was added. The mixture was stirred 5 hours at $90^{\circ} \mathrm{C}$ temperature. The polymer solution was precipitated into methanol to give a fluorescent white solid (Scheme -1).

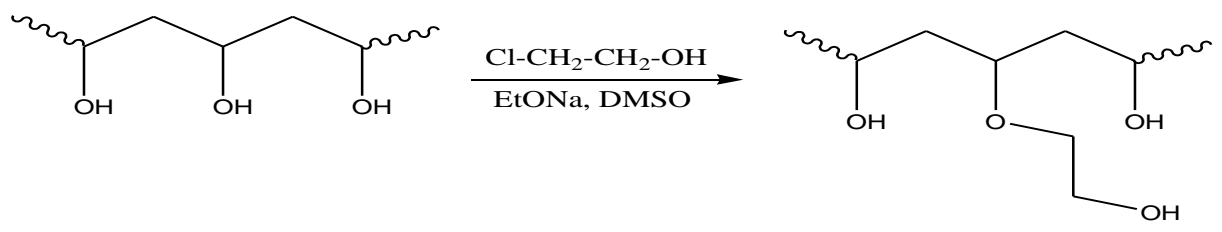

Scheme1. Hydroxyethylation of PVA with Chloroethanol

\subsection{Chloroacetylation of PVA with Chlaroacetic Acid}

Chemical Required: PVA, para-toluenesulphonic acid, 1,2-dichloroethane, chloroaceticacid.

\section{Procedure}

$40 \mathrm{~g}$ PVA and $8 \mathrm{ml}$ para-toluenesulphonic acid were dissolved in $200 \mathrm{ml}$ 1,2-dichloroethane at 110 ${ }^{\circ} \mathrm{C}$. To this solution was added $70 \mathrm{ml}$ of chloroacetic acid. The mixture was stirred at $90{ }^{\circ} \mathrm{C}$ for 1 hour. After cooling to room temperature, the polymer was precipitated by cold ethanol, dissolved in a solution of sodium carbonate in acetone and reprecipitated several times into ethanol (Scheme -2).

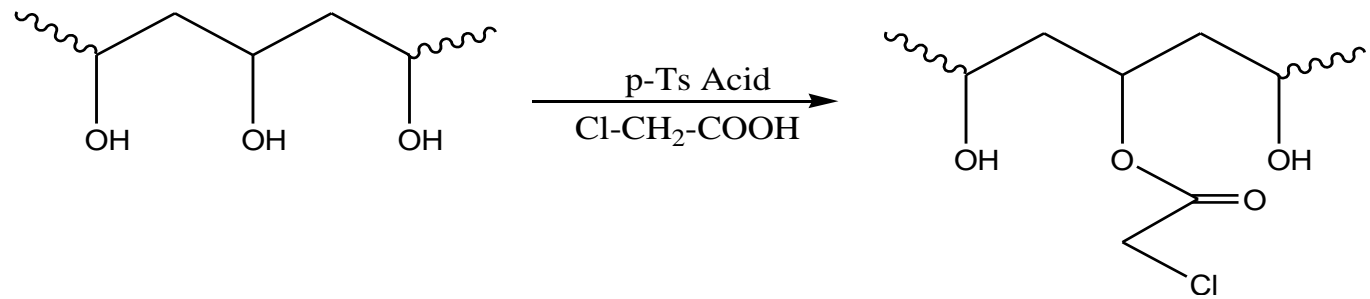

Scheme2. Chloroacetylation of PVA with Chlaroacetic Acid

\subsection{Acetalyzation of PVA with Salicylaldehyde}

Chemicals: PVA, salicylaldehyde, $5 \%$ aqueous $\mathrm{H}_{2} \mathrm{SO}_{4}$, DMSO and methanol

\section{Procedure}

A mixture of $20 \mathrm{~g}$ PVA, $32 \mathrm{ml}$ salicylaldehyde, and $20 \mathrm{ml} 5 \%$ aqueous $\mathrm{H}_{2} \mathrm{SO}_{4}$ in $200 \mathrm{ml}$ water was stirred at $60{ }^{\circ} \mathrm{C}$ for 4 hours. The precipitated Polymer was filtered and dissolved in DMSO. The polymer solution was reprecipitated by a large amount of methanol (Scheme -3).

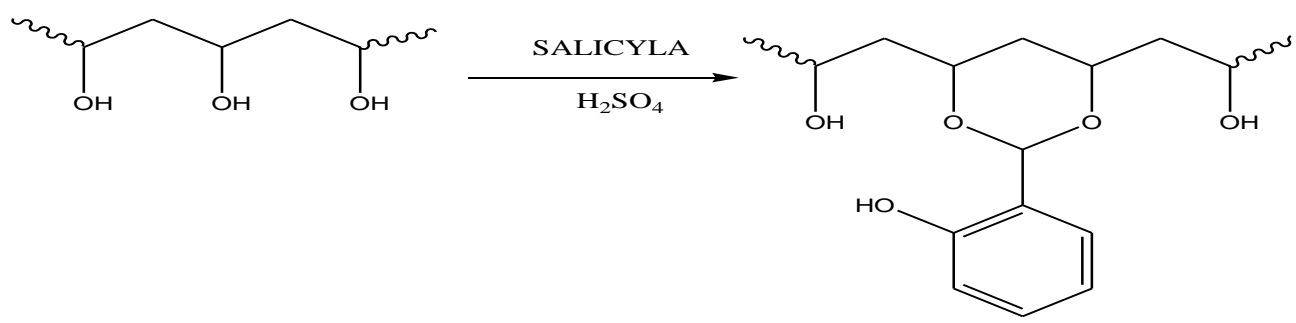

Scheme3. Acetalyzation of PVA with Salicylaldehyde

\subsection{Carboxymethylation of polyvinyl alcohol with MCAA}

Chemical Required: PVA, aqueous potassium hydroxide, monochlro acetic acid, $0.1 \mathrm{~N}$ hydrochloric acid, methanol

\section{Procedure}

The $20 \mathrm{gm}$ PVA was dissolved in $100 \mathrm{ml}$ of aqueous potassium hydroxide solution and heated in a water bath for half hour, $50 \mathrm{ml}$ of MCAA was then added and the reaction mixture was stirred at $90^{\circ} \mathrm{c}$ for 1.5 hours. At the end of the reaction the mixture was acidified with $0.1 \mathrm{~N}$ hydrochloric acid. The product was precipitated with methanol. It was then dissolved in distilled water and reprecipitated from the solution using methanol. The process was repeated till the polymer became free of chloride ions (Scheme.-4). 


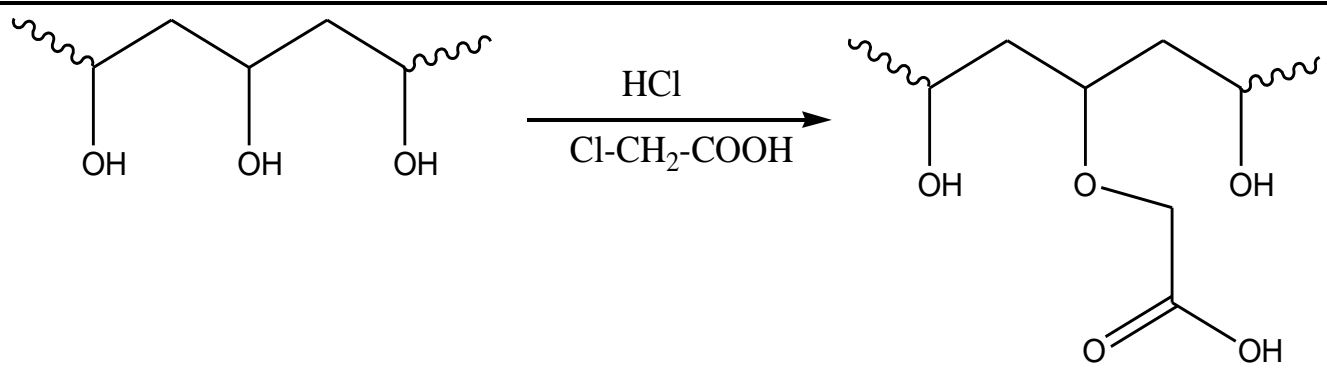

Scheme4. Carboxymethylation of polyvinyl alcohol with MCAA

\section{> Formation of Complexes of Remodulated Polyvinyl alcohols}

For the Complexes of remodulated polyvinyl alcohol likecarboxymethylated polyvinyl alcohol (CMPVA) and transition metal ions such as $\mathrm{Cu}$ (II), $\mathrm{Co}(\mathrm{II}), \mathrm{Ni}(\mathrm{II})$ and $\mathrm{Zn}(\mathrm{II})$ is used.

$\mathrm{Cu}$ (II), $\mathrm{Co}(\mathrm{II}), \mathrm{Ni}(\mathrm{II})$ and $\mathrm{Zn}$ (II ) complexes of RPVA were prepared in the ratio 1:1 (metal: RPVA), by direct mixing of $0.5 \mathrm{mmol}$ of metal salt, $0.5 \mathrm{mmol}$ of ligand in the smallest quantity of DMSO. The mixture was refluxed for 1-5 h, then they form solid complexes. The latter were separated by filtration, washed with ethanol and finally with diethyl ether.

\section{$>$ Structural Characterization}

Characterization of RPVA and CMPVA has been carried out by using XRD [12], ${ }^{1} \mathrm{H}$ NMR [13], FTIR [14]. And some important properties like, magnetic properties [15] and fluorescence properties [16] was studied in order to understand the change in polymer matrix.

\section{RESUlT AND DISCUSSION}

Fourier transform infrared FTIR spectra of all polymer conjugates under investigation were recorded on Shimadzu FTIR-8101A Spectrophotometer between 400 and $4000 \mathrm{~cm}^{-1}$.XRD patterns of the doped modified PVA samples were recorded at using Phillips PW-1700, automatic X ray-diffractometer using $\mathrm{Cu} \mathrm{K \alpha}$ radiation of wavelength $1.544 \mathrm{~A}^{0}$.UV-Visible spectra of MPVA were recorded on Shimadzu UV-1800 spectrophotometer, thin films by placing an uncoated identical conducting glass substrate in the reference beam in the range of 200 to $800 \mathrm{~nm}$. A plot of absorption coefficient verses wavelength for all synthesized samples and Wavelength for maximum absorbance $\lambda$ max and corresponding optical band gap for all samples. The ${ }^{1} \mathrm{H}$ NMR spectra of polymer conjugates were taken in a DMSO using TMS as internal standard on BruckerAuance-II 400 NMR spectrometer on $300 \mathrm{MHz}$ and $75 \mathrm{MHz}$ respectively.The chemical shifts measured are in PPM.

\section{Fourier Transform Infra-Red Spectroscopy}

FTIR characterization of RPVA and CMPVA is found to be important for investigation of polymer structure that provides information about the complexation and interactions between the various constituents in the polymeric films. Each type of bond has a different natural frequency of vibration, so the identification of an absorption peak in the vibration portion of the infrared region will give a specific type of bonding [17]. The FTIR spectra for RPVA and CMPVA are shown in Figure 1 to 2 and observed vibrational frequencies are given in Table- 1

Table1. Observed vibrational frequencies of FTIR spectra

\begin{tabular}{|l|c|c|}
\hline $\begin{array}{c}\text { S } \\
\text { NO. }\end{array}$ & Material & IR frequency in $\mathbf{~ c m}^{-\mathbf{1}}$ \\
\hline 1. & PVA & $3349,2911,1721,1660,1568,1435,1331,1094,918,851$. \\
\hline 2. & HEPVA & $3240,2510,1655,1568,1440,1330,1100,920,850, \mathbf{1 0 5 2}$. \\
\hline 3. & CMPVA & $3240,2510,1720,1655,1568,1440,1330,1100,920,850, \mathbf{1 7 1 0}$. \\
\hline 4. & CAPCA & $3340,2910,1720,1655,1568,1440,1330,1100,920,850, \mathbf{1 7 6 5}$. \\
\hline 5. & ACPVA & $3340,2910,1720,1655,1568,1440,1330,1100,920,850, \mathbf{1 1 5 5}$. \\
\hline 6. & CMPVA-Cu(II) & $3340,2910,1720,1655,1568,1440,1330,1100,920,850,1705, \mathbf{4 6 0}$ \\
\hline 7. & CMPVA-Co(II) & $3340,2910,1720,1655,1568,1440,1330,1100,920,850,1705, \mathbf{4 2 0}$ \\
\hline 8. & CMPVA-Ni(II) & $3340,2910,1720,1655,1568,1440,1330,1100,920,850,1705, \mathbf{4 5 0}$ \\
\hline 9. & CMPVA-Zn(II) & $3340,2910,1720,1655,1568,1440,1330,1100,920,850,1705, \mathbf{4 2 5}$ \\
\hline
\end{tabular}




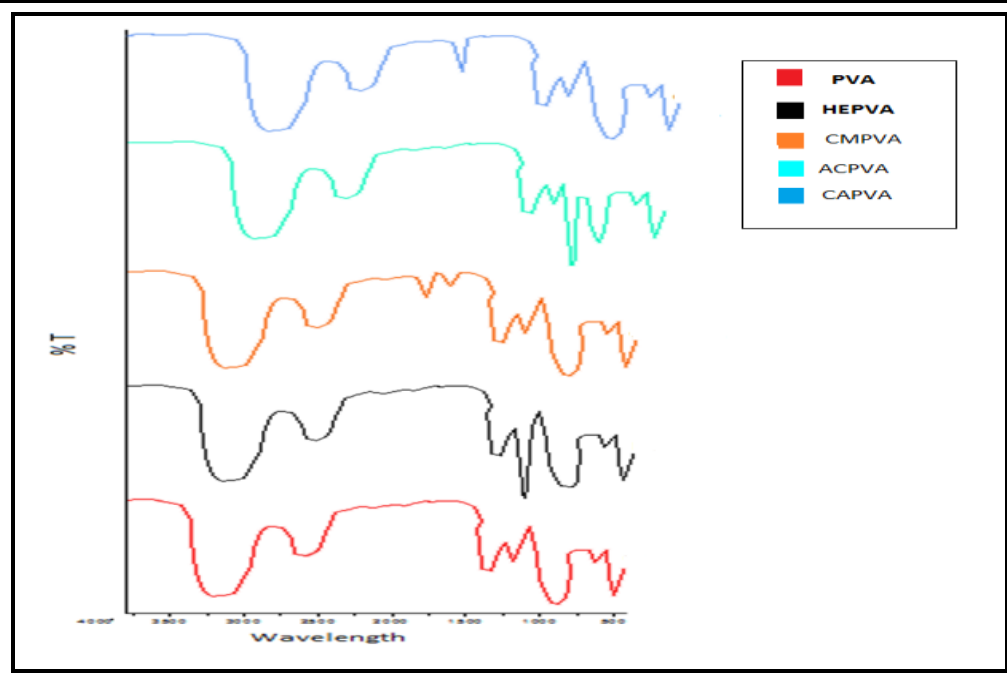

Figure1. FTIR spectra of RPVA

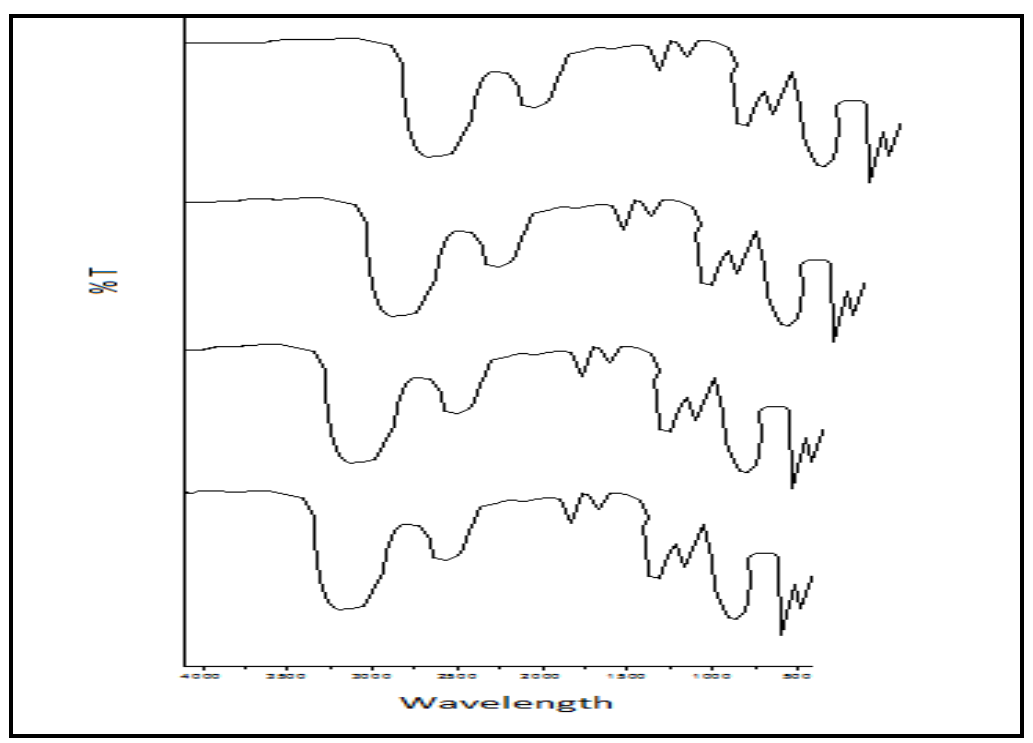

Figure2. FTIR spectra of CCMPVA

\section{Nuclear Magnetic Spectroscopy $\left({ }^{1}\right.$ H NMR Study)}

${ }^{1} \mathrm{H}$ NMR gives the information about the type of protons present in the polymer matrix. The ${ }^{1} \mathrm{H}$ NMR spectra of pure PVA, RPVA and CCMPVA as shown below,
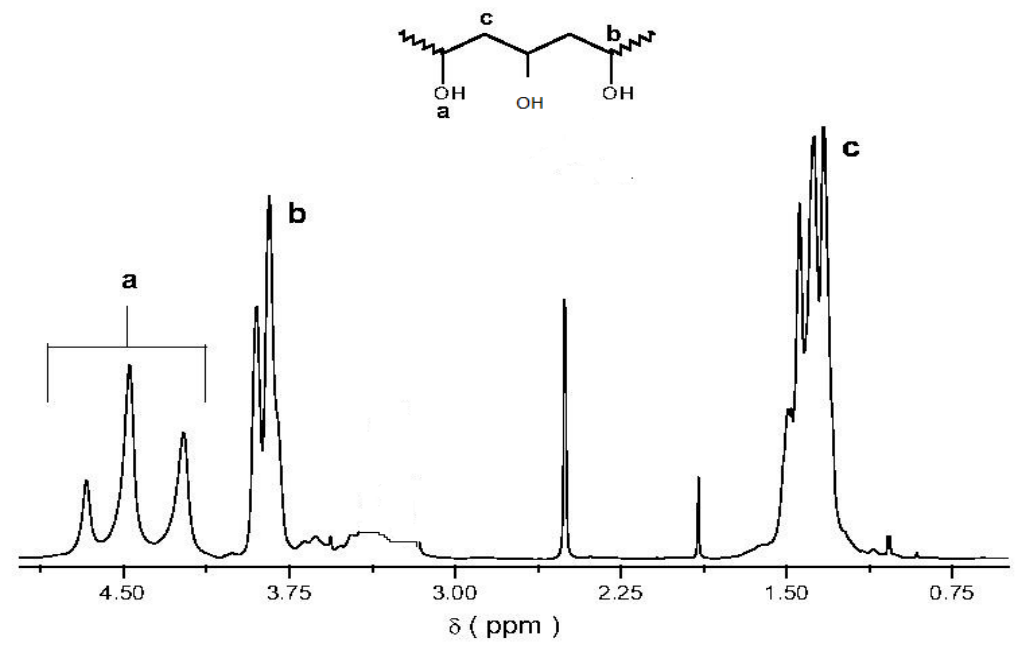

Figure3. NMR spectra of PVA 


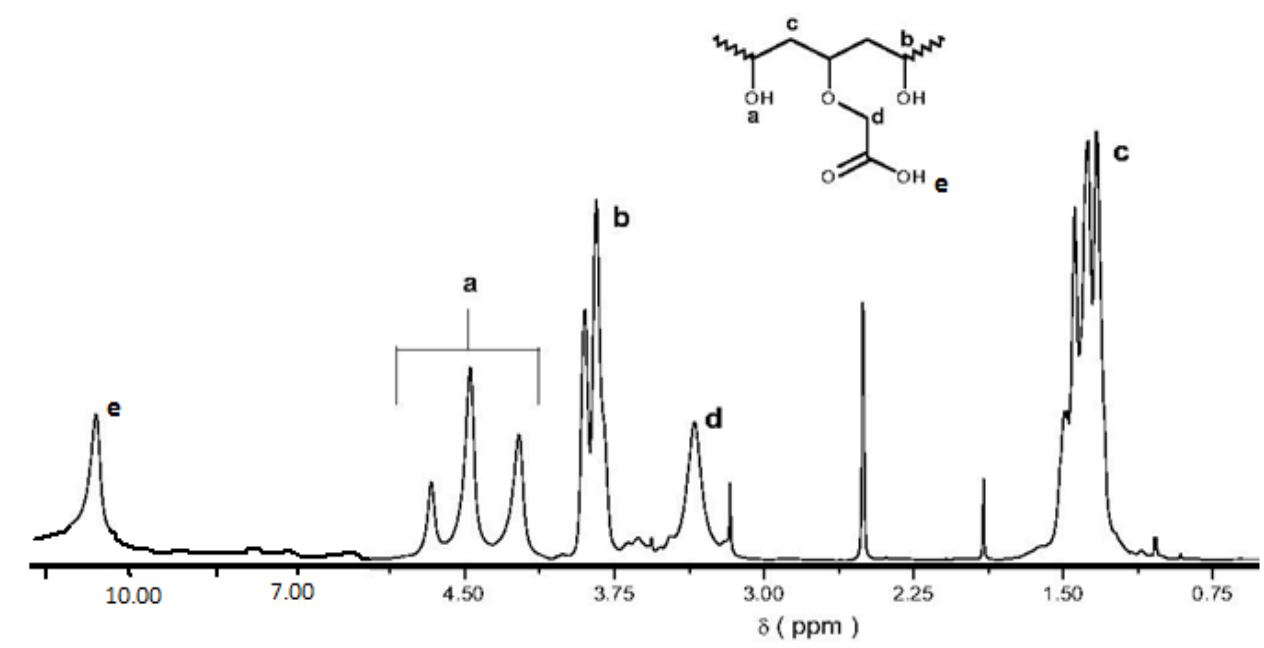

Figure4. NMR spectra of CMPVA

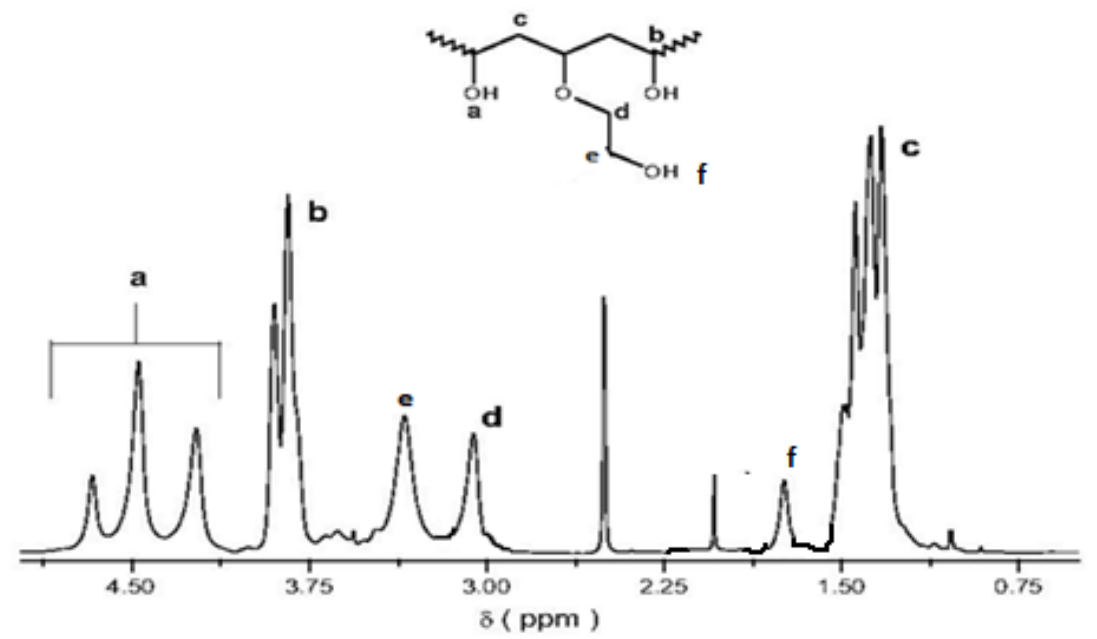

Figure5. NMR spectra of HEPVA

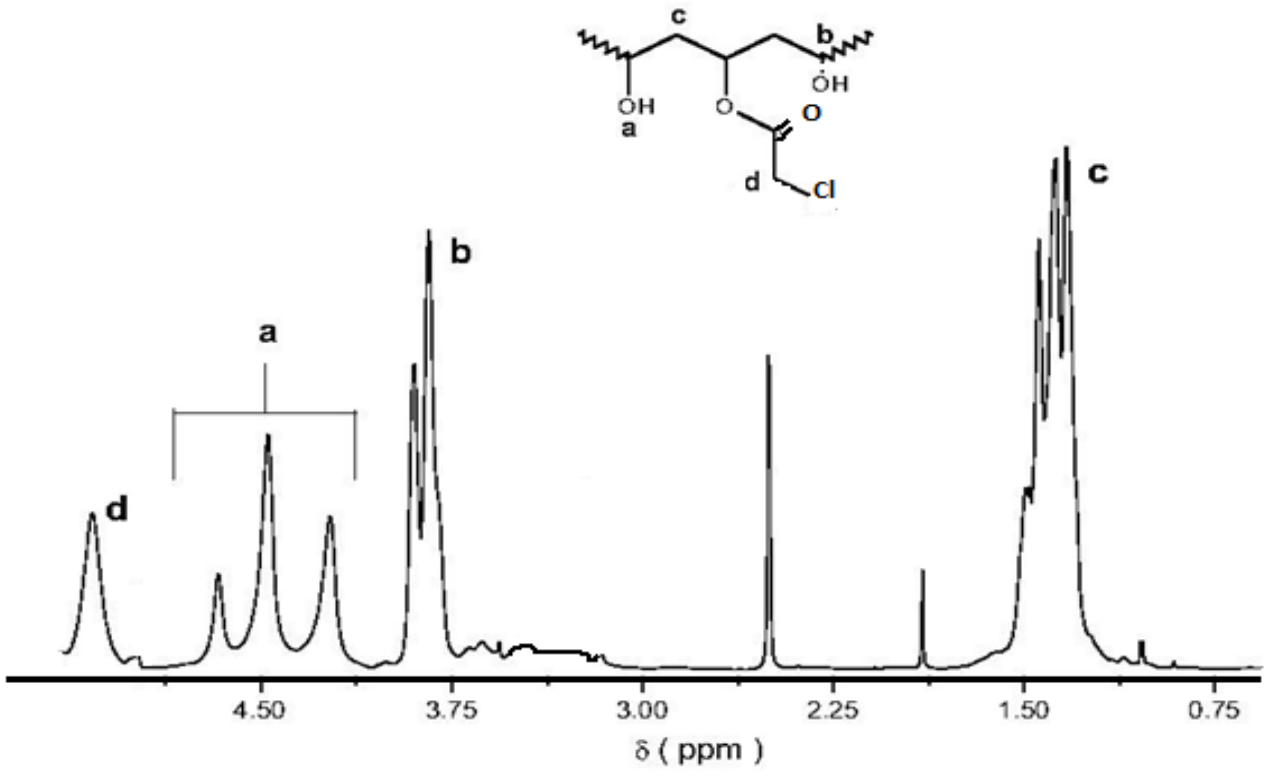

Figure6. NMR spectra of CAPVA 


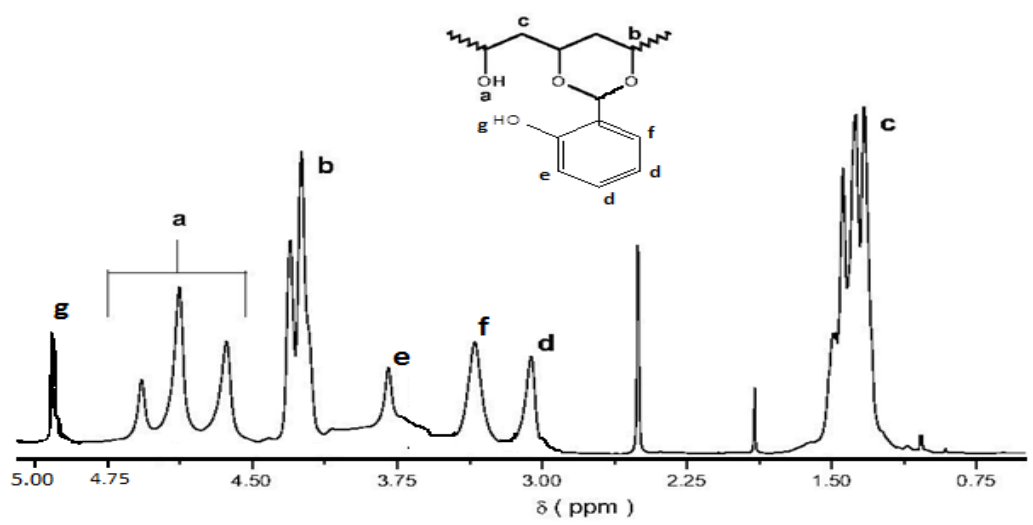

Figure7. NMR spectra of ACPVA

In CMPVA signal showed at $4.50 \mathrm{ppm}$ ( labelled a) was attributed to hydroxyl proton triads of $\mathrm{mm}$, $m r, r r$ from high to low frequency, whist the signals labeled $\mathrm{b}$ and $\mathrm{c}$ were ascribed to the PVA polymer backbone (methine and methylene protons respectively ). The signal at $3.50 \mathrm{ppm}$ and signal at $10.5 \mathrm{ppm}$ was attributed to the carboxymethyl methylene protons and carboxylic acid proton respectively.

HEPVA shows the signal at $4.51 \mathrm{ppm}$ ( labeled a) were attributed to hydroxyl proton triads of $\mathrm{mm}$, $m r, r r$ from high to low frequency, whist the signal labeled b (3.80) and c (1.45) were ascribed to the PVA polymer backbone (methine and methylene protons respectively). The signals at $3.50 \mathrm{ppm}, 3.12$ ppm and $1.75 \mathrm{ppm}$ were attributed to the chloroethylene methylene protons and hydroxyl proton respectively.

ACPVA shows the signal at $4.65 \mathrm{ppm}$ ( labeled a) were attributed to hydroxyl proton triads of $\mathrm{mm}$, $m r, r r$ from high to low frequency, whist the signal labeled $\mathrm{b}(4.25)$ and $\mathrm{c}(1.40)$ were ascribed to the PVA polymer backbone (methine and methylene protons respectively ). The signal at 3.80, 3.50, 3.20 and $4.95 \mathrm{ppm}$ was attributed to the aromatic methylene and hydroxyl protonsrespectively.

CAPVA shows the signal at $4.50 \mathrm{ppm}$ ( labeled a) were attributed to hydroxyl proton triads of $\mathrm{mm}$, $m r$, rrfrom high to low frequency, whist the signal labeled b (3.80) and c (1.45) were ascribed to the PVA polymer backbone (methine and methylene protons respectively ). The signal at $5.10 \mathrm{ppm}$ was attributed to the chlaroacetic methylene protons. Unfortunately there is no relevant data in literature to confirm this.

The signals at $3.16,2.48$ and $1.89 \mathrm{ppm}$ were attributable to the following solvent contaminants methonal, DMSO and acetic acid respectively.

The NMR spectrum of CCMPVA clearly indicates that the chemical shift values are going to downfield. The signal at $4.50 \mathrm{ppm}$ were attributed to hydroxyl proton triads of $\mathrm{mm}, \mathrm{mr}, \mathrm{rrfrom}$ high to low frequency shifted to 4.25, 4.20, 4.10, 4.05 for CMPVA-Cu(II), CMPVA-Co(II), CMPVA-Ni(II) and CMPVA-Zn(II) respectively. Whist the signal labeled $\mathrm{b}$ and $\mathrm{c}$ were ascribed to the PVA polymer backbone (methine and methylene protons respectively) also shifted to downfield. The signal at 3.50 ppm was attributed to the carboxymethyl methylene protons also shifted.

\section{$>$ X-Ray Diffraction (XRD)}

The XRD profiles of pure PVA, RPVA and CCMPVA with transition metal ions are shown in Figure 8 and 9.

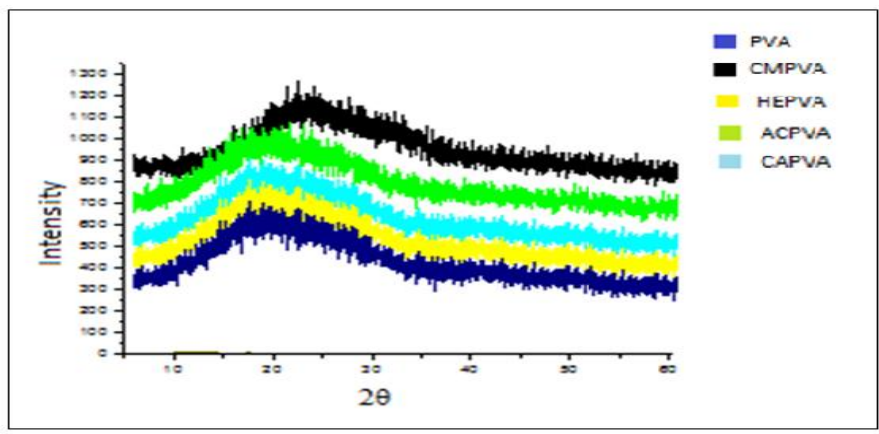

Figure8. XRD Spectra of pure PVA and RPVA 
Figure. 8 shows the $x$-ray diffraction of PVA and RPVA samples at room temperature in the scanning range $6^{\circ} \leq 2 \theta \leq 60^{\circ}$. Spectrum of pure PVA shows an intense reflection peak at $2 \theta=19.9^{\circ}$ diffused in the hallow amorphous region and was assigned to a mixture of (101) and (101) reflections [18]. The appearance of sharp reflections and diffuse scattering is characteristic of crystalline and amorphous phases of conventional semi-crystalline polymers [19]. However, spectrum of CMPVA shows a broad amorphous halo with a scattered intensity, maximum corresponding to $2 \theta=22^{\circ}$. It reflects the absence of any diffraction lines, indicating the amorphous nature of CMPVA It is known that glassy amorphous polymers are typically optically clear; showing a liquid-like x-ray pattern [19]. XRD patterns HEPVA and CAPVA of samples exhibited the characteristics of pure PVA, but with less intensity for the reflection peak. Thus, one can say that the semi-crystalline structure of PVA decreases upon modification. However, XRD pattern ACPVA shows an intense broad halo amorphous covering the positions of those found in homopolymers, for the semicrystalline/amorphous nature, the non-crystallizing component could strongly modify the crystallization behavior of crystallizing component [20]. For RPVAs, compatibility between the amorphous components of both homopolymers is possible. Thus, it can be suggested that the crystal forms in PVA do not prevent the compatibility between amorphous regions of the two polymers.

XRD patterns exhibited strong diffraction peaks at $25^{\circ}, 36^{\circ}$ and $55^{\circ}$ indicating transition metal ions in the rutile phase and strong diffraction peaks at $22^{\circ}$ and $42^{\circ}$ indicating transition metal ions in the anatase phase. CCMPVA shows characteristic broad peak for an orthorhombic lattice centered at $19^{0}$ to $22^{0}$ including semi crystalline nature of all CCMPVA [21]. With addition of transition metal ions, intensity of this peak decreases, suggesting the decrease in degree of crystallinity of the complex [22]. This may be due to the disruption of the CMPVA crystalline structure by transition metal ions as suggested [23].

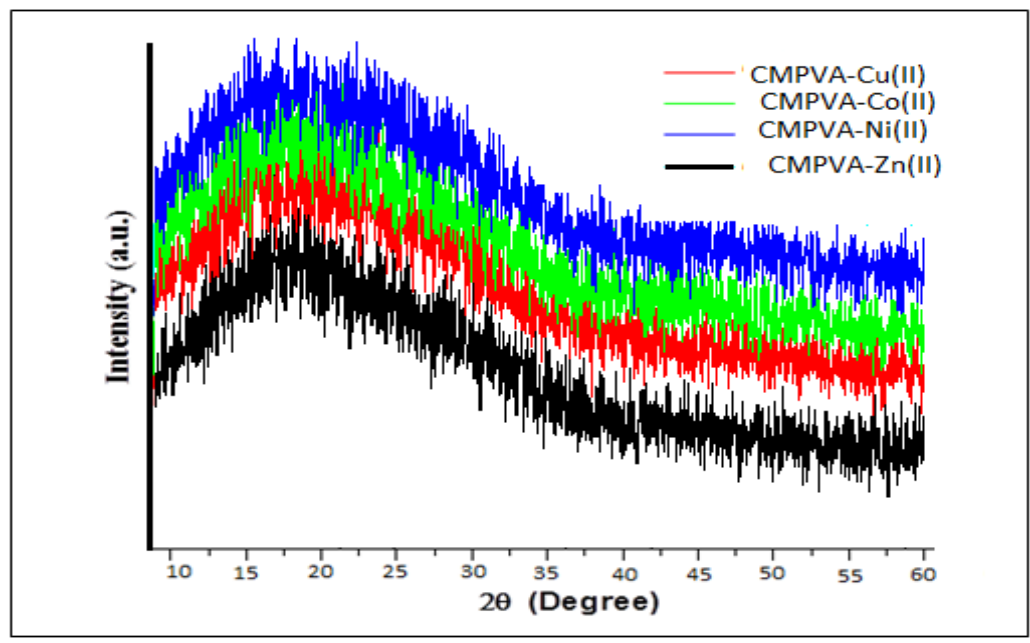

Figure9. XRD Spectra of CCMPVA

\section{REFERENCES}

[1] S.M. Burkinshaw, N.A. Kumar, Dyes and Pigments 77 (2008) 86-91.

[2] N. Hojo, H. Shirai, S. Hayashi, J. Polym. Sci. Polym. Symp. 47 (1974) 299-307.

[3] A.A. Shoukry, W.M. Hosny, Cen. Eur. J. Chem. 10 (2012) 59-70.

[4] C. Vasile, A.K. Kulshreshtha, Handbook of Polymer Blends and Composites, Rapra Technology. Ltd.: Shawbury, UK, 2003, pp. 288-365.

[5] B. Ratner, A.S. Hoffman, F.J. Schoen, J.E. Lemons, Biomaterials science: An introduction to materials in medicine, Elsevier Academic Press, San Diego, 2004.

[6] C.M. Hassan, N.A. Peppas, Adv. Polym. Sci. 153 (2000) 37-65.

[7] Rajendran S., Sivakumar M., Subadevi R.; Mater. Lett., 58, (2004), 641.

[8] Abdelaziz M., Abdelrazek E.M.; Phys. B, 349, (2004), 84.

[9] Zhang Q., Whatmore R.W.; J. Phys. D, 34, (2001), 2296.Hema M., Selvasekarapandian M., G. Hirankumar, Sakunthala, D. Arunkumar and H. Nithya; J. Phys. Chem. Solids, 70, (2009), 10981103. 
[10] El-Khodary A.; Physica B, 404, (2009), 1287-1294.

[11] Kavita B., Dasharatham D.; JCPS, 4(4), (2011), 155.

[12] Ravindranadh K., Avikumar A., RAO M.C.; Journal of Non-Oxide Glasses, 5(3), (2013), 39.

[13] ChilingaRaju, Rao J.L., Reddy B.C., and VeeraBrahmam K.; Bull. Mater. Sci., 30(3), (2007), 215-218.

[14] Patachia S., Rinja M., Isac L.; Rom. Journ. Phys., 51(1-2), (2006), 253-262.

[15] WieslawaFerenc, PawelSadowski; J. Chil. Chem. Soc., 58(2), (2013).

[16] Osiris W. Guirguis, Manal T. H. Moselhey; Natural Science, .4(1), (2012), 57-67.

[17] Roman Jantas, ZbigniewDraczynski, LucynaHerczynska, DawidStawski American; Journal of Polymer Science, 2(5), (2012), 79-84.

[18] Friedlander H.N., Harris H.E. and Pritchard J.G.; J. Polym. Sci. part A-1: Polymer chemistry, 4, (2003), 649.

[19] Wignall G.D., Scattering Techniques, in physical properties of polymers, American chemical Society, Washington DC, (1993).

[20] Cheung Y.W. and Guest M. J.; J. Polym. Sci. Part B: Polym. Phys., 38, (2000), 2976.

[21] Shehap A., Abd Allah R.A., Basha A.F. and Abd El-Kader F.H.; J.Appl.Polym.Sci., 68, (1998), 687-698.

[22] Ramesh S. and Arof A.K.; J. Power sources, 99, (2001), $41-47$.

[23] A.H. Basta, W.M. Hosny, Polym. Deg. and Stab. , 60 (1998) 239-245.

Citation: G. Murhekar, "Synthesis and Characterization of Complexes of Remodulated Polyvinyl Alcohol Conjugates", International Journal of Advanced Research in Chemical Science (IJARCS), vol. 4, no. 4, p. 39, 2017. http://dx.doi.org/10.20431/2349-0403.0404004

Copyright: (C) 2017 Authors. This is an open-access article distributed under the terms of the Creative Commons Attribution License, which permits unrestricted use, distribution, and reproduction in any medium, provided the original author and source are credited. 